\title{
13. Mapping Genocide? Giving Visual Memory to Oral Culture
}

\author{
Sebastian Maisel
}

\begin{abstract}
Yezidi religion and history had been largely transmitted orally until the late $20^{\text {th }}$ century due to the closeness, isolation, and marginalization of the community in their various home countries. It was the advent of digitization that sparked a radical switch and concurrent emergence of a new class of protagonists who used social media as a tool to theorize and generalize sacred knowledge. The new actors often do not belong to the traditional class of clergy in charge of preserving and transmitting this information. In this chapter, I argue that their use of social media to spread deliberate knowledge has contributed to the development of new forms of identity and loyalty among Yezidi groups in Syria and Iraq.
\end{abstract}

Keywords: Yezidi, genocide, new media, memory

In August 2014, the Yezidi community in Iraq endured yet another genocidal attack when the radical Islamist and terror organization ISIS targeted the community in the Sinjar Mountain region. The attack included mass killings, kidnapping and enslavement of women and children, forced exile, and the destruction and looting of property and sacred buildings. Because of the magnitude of the event, the Yezidi community reacted differently to this attack than in the past. Yezidi activists, many of them women and survivors, broke with age-old customs, taboos, and traditions by publicly giving testimony to the atrocities and crimes committed against them. They did so by using their education and technological skills to promote their narratives. This story, which can be labelled 'Victims seeking Justice', reflects the transformation of Yezidi collective identity and the transmission of religious knowledge.

Yezidi religion and history have been largely transmitted orally until the late $20^{\text {th }}$ century due to the closeness, isolation, and marginalization of the 
community in their various home countries. A new class of protagonists emerged since the digital era reached the Yezidi community. They use social media as a tool to theorize and generalize sacred knowledge and social conventions. The new actors often do not belong to the traditional class of clergy or patriarchal community leaders, who used to be in charge of preserving and transmitting this information. Effectively, we note an increased exposure to sacred knowledge as well as a reinterpretation of social dogmas by unorthodox scholars, activists, intellectuals, and politicians. In this chapter, I argue that their use of social media to spread deliberate knowledge has contributed to the development of new forms of identity and loyalty among Yezidi groups in Syria and Iraq. The Sinjar genocide accelerated this process.

\section{Methodology}

The main objective of this chapter is to understand how the visualization of survivors' memories spark social change. I will do this by discussing the relationship between social change, collective identity, and the production and circulation of both sacred and profane knowledge. This process traces the mapping of indigenous geographies, which is viewed as a means to establish new levels of authority and legitimacy within the Yezidi community.

Sources evaluated for this study include interviews with Yezidis from different social and religious groups, educational levels, and regional backgrounds. In addition to the oral narratives, official Iraqi, Syrian, German, and Yezidi documents from governmental and private archives were analysed to supplement the empirical data. In addition, several other mapping projects with Yezidi collaborators, to which the author contributed, will be introduced in this chapter.

Aside from ethnographic methods of inquiry such as participant observation or key informant interviews, this chapter also relies on social media practices and technologies as part of the fieldwork. In addition to the mapping project, popular social media sites such as Twitter, Facebook, and YouTube were accessed to communicate with distant informants, retrieve otherwise inaccessible data, and observe Yezidi practices of selfrepresentation. Especially when informants and localities are located in areas of war and conflict, thus making it impossible to conduct traditional fieldwork, researchers refer to online sources. With the spread of technologies such as mobile phones and computers, the target community is more capable of sharing unfiltered and live information. For the distant analyst 
and observer, the raw material, documents, films, images, and other items become primary sources of high importance.

In case of the Yezidis, the number of primary sources prior to digitization was extremely small. However, over the past decade, Yezidis from all areas have gained access to various technologies and have used them vigorously to share files, photos, messages, and other information with each other and the rest of the world. Following the guidelines and recommendations of Hine (2008) as well as Poster and Pink (2012), the data was used to shape the opinion of the author and the argument of this chapter.

\section{Introduction}

To depict emerging social hierarchies, this chapter will highlight the shift in transmitting sacred and profane knowledge among the Yezidis using new tools and technologies at home and abroad in times of crisis.

The Yezidis, like other indigenous ancient religious and ethnic communities in northern Mesopotamia, have been described in hierarchical, segmented terms. Their religious structure is defined by the separation between clerics and laypeople. Most Yezidis support the idea of identifying with Kurdish origin and ethnicity, while some prefer a distinct Yezidi ancestry as a unique ethno-religious group. Spatially, the community is divided among several host countries including Iraq, Syria, Turkey, Armenia, Georgia, and the diaspora in Europe and North America.

Throughout history, they have been exposed to numerous periods of upheaval and instability. But since the time of nation-building in the Middle East after World War I, Yezidis have experienced periods of intense, largescale population upheavals, often involuntarily due to forced displacement, ethnic and religious violence, and government interventions, some of which can be described as genocide. This study aims to investigate how recent events such as war, genocide, political change, and the promotion of specific identities have 1) affected the traditional Yezidi communities directly; 2) impacted gender roles; and 3) created new hierarchies based on the application of new digital media.

\section{Traditional Yezidi Society}

Religious authority within Yezidi society is concentrated in the hands of a few hereditary families who also represent the two main clerical castes of 
Sheikh and Pir. This system of authority was reformed in the twelfth century by Sheikh Adi bin Musafir, a historic figure with strong connections to Sufi Islam. Prior to his arrival in the Hakkari Mountains, where the community lived, they already practised a proto form of Yezidism that incorporated elements of sun worship and likely Zoroastrianism. A group of religious leaders, the Pirs, stood above the general population of laypeople. Sheikh Adi added another group of clerics, the Sheikhs, and prescribed distinct marriage and interaction rules known as sed $u$ hed. These rules define Yezidi society along three distinct groups, sometimes called castes, which were not permitted to intermarry and which were to guide and instruct each other. The descendants of Sheikh Adi have maintained political leadership over the community to the present day.

Little is known about the various Yezidi communities during the Ottoman Empire other that they lived secretive, reclusive lives at the periphery of society. Ottoman court records, French missionary reports, and British travellers' accounts, however, depict a community life similar to that of Sheikh Adi's time. They chose to live on the fringes away from the urban centre because of the continual discrimination by their Muslim neighbours, which resulted in mass killings, deportations, forced conversions, enslavement, and general destruction of their livelihood. The reports, however, also talk about the preservation of ancient customs (sed $u$ hed) and unique religious convictions. Similar to their Muslim Kurdish neighbours, the Yezidis maintained a patriarchal, tribal family structure, which was economically based on farming and animal husbandry. In contrast to their Muslim neighbours, Yezidi communities made efforts not to integrate or assimilate with mainstream Ottoman, Kurdish, or Arab lifestyles. Instead, they favoured disassociation and avoiding cultural and/or religious exchange to a degree that the Yezidis in Sheikhan and Sinjar were known for their illiteracy. The leadership decided it was more beneficial for the community not to allow Islamic education to be spread among them. They argued that it was better to have no education than to be affected by Muslim da'wa ('proselytizing') and the kuttab (Koran schools). Thus, knowledge was concentrated in the hands of a few learned men while the rest of the community remained unexposed to religious (including Yezidism) and secular education until World War I.

With the establishment of nation states, which focused on nation-building through public education, the Yezidi communities in Turkey, Iraq, and Syria were no longer able to withhold their children from mandatory attendance at schools, where they were often forced to participate in Islamic education. Since the Yezidis were not recognized as an autonomous millet (an autonomous religious or ethnic community in the Ottoman Empire), they 
were not granted special treatment and ownership of their religious affairs and education. This also enabled governments to extend conscription laws to the Yezidis, which the community strongly opposed. Their motto of survival was still disengagement at all costs, and the community leadership in Iraq tried everything to avoid nationalistic, sectarian, or political conflicts.

The situation in Syria was less tense because the Yezidi community there was much smaller and already deeply embedded in the Kurdish sector (Maisel 2017). There was even a certain degree of tolerance towards the Yezidis, especially in the Efrin region, where Yezidi settlements can be traced back to the sixteenth century. Thus, the policies of anti-educational disengagement did not apply here. On the contrary, Yezidi community leaders such as Darwish Shamo actively pursued religious and secular education in their villages. In 1925, Shamo opened the first Yezidi School in the village of Qibare, and a Yezidi teacher from Iraq was hired to teach, among other topics, Yezidi religion. The minority-friendly attitudes of the French mandate powers allowed this to happen. When Syrian nationalists took over Syria after the country had become independent, Yezidism was no longer a permitted topic to teach. This and the physical disconnect from the main Yezidi territories in Iraq led to the formation of a diverse Yezidi identity in Syria - one that saw a decreased influence of clerics over community and identity-building measures. This void was often filled by educated laypeople, a process that has continued to the present day. Moreover, with the current political and demographic changes in Rojava (the Kurdish territories in Syria), such as the rise of the PYD (Partiya Yekitiya Demokrat) and the establishment of self-autonomy, there might be greater changes for the Yezidi community in Syria and their role in shaping the future society.

\section{New Gender Roles}

In all Yezidi territories, including among the diaspora communities, gender roles have transformed. The traditional model of the patriarchal family is still widely accepted, but the recent experiences in Syria and Iraq, both traumatic and positive, pushed for a bigger role for Yezidi women in community life. The religious sphere, however, is less affected, and women are still largely excluded from it. Traditionally, they have played a minor role in the transmission of sacred knowledge. While Yezidi women have to select two female spiritual mentors (Sheikh and Pir) and a sister in the hereafter, these functions are largely passive. The only important role Yezidi women play in the religious landscape is a supportive one during weddings and 
funerals, where they often contribute with laments, traditional hymns, and other songs.

As such, very few historic female role models could have inspired Yezidi women to seek a more active role in social and religious life. Certainly, until the end of the $20^{\text {th }}$ century, they were stuck in the traditional, patriarchal society where they had specific obligations and functions to fulfil. Seeking education, either secular or religious, was not one of those tasks. Some Yezidi women gained wider popularity throughout history mainly because of their political or social activism. They include the Grand Dame of Yezidism, Mayan Khatun, and some other female members of the Mir family. However, since the outbreak of the Kurdish national struggle and the limited involvement of Yezidi organizations, more Yezidi women from various backgrounds have used this platform to present a new image of Yezidi womanhood. In particular, the role Kurdish Yezidi women play in the PKK (Partiya Karkerên Kurdistanê) as politicians, fighters, activists, or supporters is noteworthy. The area of operation covered the Yezidi territories in Turkey, Iraq, and Syria, and the fallen members were always honoured and held in high esteem. A small number of Yezidi women from Turkey and Syria were among them. The number of Yezidi female fighters increased during the early years of the Syrian civil war, when many joined the Women's Protection or Defense Units YPJ (Yekineyên Parastina Jin) in the battle against ISIS and other radical Islamic groups. Others joined the Asayish police force or the autonomous self-administration in high-ranking positions. The PYD has a women quota and a female co-chair, and similarly, Syrian Yezidi women became involved in the local politics of Rojava. Especially in the Efrin Canton, Yezidi women's organizations are particularly active and successful in promoting women's rights, the Yezidi religion, and the Kurdish national struggle. They use social media to connect and organize events and spread awareness among the general Kurdish population as well as the Yezidi diaspora.

The general access to the internet and availability of computers and more so of mobile phones have contributed much to enabling Yezidi women in Syria and Iraq to communicate their side of the story to a widespread and international audience. While they may be semi-analphabet, they know how to use technology to better connect and communicate with each other. The live newsfeeds from Mount Sinjar were crucial in shaping public Western opinion about getting involved and starting the air rescue campaign. Many Yezidi women were able to hide their mobile phones in ISIS captivity and convey messages and coordinates to their families. Moreover, while the past massacres against the Yezidis went almost unnoticed, the latest one was brought directly into the living rooms of the entire world by television. 
The Yezidis finally caught the world's attention, but the consequences were brutal. While the Western world started a campaign to free some two hundred abducted Nigerian pupils, the number of kidnapped and enslaved Yezidi women and children reached almost ten thousand. Over the past three years, about half were eventually rescued, freed, ransomed, or managed to escape, which still leaves several thousand in ISIS captivity.

ISIS's campaign against the Yezidis has been qualified as genocide. ${ }^{1}$ It follows a common pattern as the genocides in Armenia, Bosnia, or Rwanda: forced conversions, separation of men and women and children, mass execution of men above twelve, enslavement of young women and children, looting and destruction of property, and training and indoctrination of young Yezidi boys in ISIS camps.

Moreover, while ISIS indiscriminately and brutally attacks Sunnis, Shias, Druze, and Christians, they make special efforts to eliminate the Yezidis. ${ }^{2}$ It must be noted, however, that this is not a new phenomenon. Intolerant and violent attitudes among the Muslim population in northern Iraq were observed long before the August 2014 attacks. ISIS is just the latest addition to the group of anti-Yezidi perpetrators. What is new is the methodology, justification, and technology of the genocide. ISIS is very transparent about their intentions and goals, one of which is the eradication of Yezidis from the area.

In their official publication, Dabiq, self-styled ISIS clerics try to explain the Islamic rationale that justifies the sexual enslavement of women from communities determined to be of 'pagan' or 'polytheistic' origin. Here, ISIS speaks of greater efforts to exterminate Yezidis; differentiates between People of the Book, apostates, and polytheists (Yezidis); justifies the enslavement of polytheist women as a custom of the early Muslim community; and describes the 'benefits' of having a relationship with a slave women over a prostitute (Dabiq 2015, pp. 14-17). A female ISIS writer providing scriptural and historic justification for the term saby ('female captive') further clarified this (Dabiq 2015, pp. 45-49). In addition, ISIS released a Q \& A memorandum detailing the interaction with and treatment of the sabaya. ${ }^{3}$ Finally, ISIS fighters and supporters use social media to share their experiences. At one

1 See the report 'They Came to Destroy - ISIS Crimes Against the Yezidis', published by the UN Commission of Inquiry (COI) on Syria at: http://www.ohchr.org/Documents/HRBodies/ HRCouncil/CoISyria/A_HRC_32_CRP.2_en.pdf.

2 While Christians were given three options by ISIS - to convert, to leave, or to pay a special head tax - Yezidis had to choose between conversion and execution.

3 'Islamic State (ISIS) Releases Pamphlet On Female Slaves', 4 December 2014, http://www. memrijttm.org/islamic-state-isis-releases-pamphlet-on-female-slaves.html\#_ednı. 
point, it was reported that Yezidi women were sold online, and manuals and flyers of appropriate customer behaviour were circulated.

Considering the traditional character of Yezidi society, with their unique interpretation of honour and shame, one could assume that the crimes committed against Yezidi women would tarnish their reputation, and that they would not be allowed to return to their communities. This was the common reaction to similar incidents prior to the Sinjar massacre. Yezidi women have been kidnapped, converted to Islam, and married off to Muslim men in the past, and their ties with their Yezidi families were frequently completely severed (Kreyenbroek 2009, pp. 40-45 and pp. 50-55). However, despite the massive group and individual trauma, the community reacted differently in this case and welcomed back the women freed from ISIS captivity. Moreover, while the Yezidi religious leadership with the Mir, the Baba Sheikh, and the Spiritual Council have been rather silent or perhaps overwhelmed and paralyzed by the atrocities, they did make one important public announcement: the official and religious embracing of the Yezidi women into the community with special blessings, baptisms, and official decrees.

Yezidi women themselves, however, were the real activists for Yezidi women, refugees, and justice. Often traumatized survivors, they reached out to the world to publicize their horrific stories in an act of defiance towards traditional values and customs. Talking about rape and other sexual crimes used to be taboo; however, sharing their stories was not only an act of great personal courage but also ignited a campaign to raise awareness of the crimes and awareness of the great number of women still held captive by ISIS. Many Yezidi men have been killed, but Yezidi women continue to live with the ordeal, and some Yezidi women use social media to advocate for them. With this increased publicity, they have taken on new leadership roles in the community, certainly not in a religious capacity, but with great impact on gender roles and hierarchies within Yezidi society.

Vian Dakhil is the most prominent among these women activists. A member of the Iraqi parliament and from an upper-class family in Sinjar, she has used her elevated position to raise awareness about the genocide inside Iraq and around the world. Other women, such as Nadia Murad, Lamia Bashar, and Farida Khalaf, are survivors of ISIS sexual slavery. ${ }^{4}$ By bravely sharing their experiences with the world, they broke taboos and the barriers of ignorance and social hierarchies. Bari Ibrahim is a Yezidi advocate from the diaspora group, and she has managed to raise awareness and aid for the 
community in Sinjar. These five women symbolize the new Yezidi woman who represents the community from within and to the world.

\section{Building New Hierarchies}

Before August 2014, Yezidi society in Iraq was known for its strict religious observances, marriage rules, and patriarchies. As mentioned earlier, secular education did not spread among the villages until the 196os. Furthermore, a religious education for the masses had not even started yet (with exceptions in the diaspora). It was only in the 1970s when young Yezidi academics (from religious families) started to collect oral histories and texts with the aim of releasing them and spreading the information among the Yezidi masses. Pir Khidr Suleyman and Khalil Jindy from Iraq, and Celil and Celile from Armenia, were among those pioneers who recorded the first poems, hymns, psalms, and religious chants and later transcribed and translated them (Celil and Celile 1978; Suleyman and Jindy 1979). With increasing publication opportunities, these texts eventually made it into the first textbooks on the Yezidi religion. However, they were not allowed to be used in Syrian, Turkish, or Iraqi schools, so it was left for the diaspora community to organize the first lessons in Yezidism. Yezidis in Germany were also among the first to publish newspapers, journals, and books in the 1990s when Yezidi studies was still in its infancy. The writers, publishers, organizers, and activists mainly belonged to the laypeople's caste, the mirid. Frequently, the clergy debunked, criticized, and rejected these works. However, in groundbreaking work, this new, second generation of Yezidi emigrants opened up the debate and included various stakeholders, including women, youth, and laypeople.

Two other facts contributed to the formation of a new leadership: first, their higher educational level and media savviness, and second, the absence of a new generation of active clergy. Thus, the new leaders filled a gap and provided the community with long sought-after answers to their identity struggle. As such and for the first time, Yezidis were reimagining their life and religion with input from the entire socio-religious spectrum. Religious instruction and intellectual debate were no longer restricted to a particular group, but allowed for the inclusion of every member of Yezidi society.

Eventually, this debate travelled back to the home countries, where new political realities helped the Yezidi communities to receive this message with open minds. Increased technological connectivity as well as increased mobility triggered a vibrant dialogue among the different geographical regions, generations, and religious castes, including attempts to 'highjack' certain 
religious dogmas or rituals and other attempts to disqualify nonconformist communities and opinions. While each side held their own conferences and meetings, it was in the online world where they were able to meet and discuss directly, including in forums, blogs, news sites, and social media.

\section{Mapping the New Yezidi World}

Both Arab and Kurdish nationalists have used maps as an instrument of oppression. In their discourse to instrumentalize the Yezidis, they have relied on other forms of (mis)representation such as the census and museums. Benedict Anderson singles out maps as instruments of power that profoundly shaped the way in which the colonial state imagined its dominion - the nature of the human beings it ruled, the geography of its domain, and the legitimacy of its ancestry (Anderson 2006, pp. 163-164). In the new Yezidi world - the one after genocide - Yezidis have turned the tools against the former master. Now, Yezidis use maps and other forms of representation to self-consciously control their discourse and define their domain. Like other indigenous peoples, they try to reverse histories and geographies of dispossession and discrimination, establishing what Coombes calls 'indigenous histories and geographies' to reconceptualize their participation and action (Coombes et al. 2014, pp. 845-854).

It appears that the Yezidi attempts to do that reveal several underlying trends. The current Yezidi media landscape reflects the political, spiritual, and social division among the many Yezidi communities in the homeland and in the diaspora. Although we have noted a process of reimagining Yezidi theology and a concurrent, ongoing debate over values and dogmas, this has not translated into the emergence of a unified Yezidi identity. Political calculations, strategic considerations, economic interests, and power struggles have made it impossible for the minority to rally behind a common goal. Instead, competing geographical backgrounds and party affiliations dominate the daily discourse. Each interest group has access to and is represented by influential media outlets, which diligently report one-sided stories and accusations, and claim the sole status of representation and victimhood.

Various influential outlets are omnipresent in today's Yezidi media landscape; among the most popular are two sites that operate from within the Yezidi homeland: Bahzani ${ }^{5}$ and Lalishduhok. ${ }^{6}$ Both sites are, however, extremely partial to Yezidi events inside Iraq and only rarely report on affairs 
from Syria or the diaspora, and never from Armenia. Lalishduhok is also the mother company for well-known Yezidi journals and newspapers, including Majallat Lalish, Denge Lalish, and some other publications by local branches of the Lalish Cultural Centre, which receives most of its funding from the KDP (Partiya Demokrat a Kurdistanê). The small number of printed hard copies is now substituted by a complete and free online version.

A recent addition to the online news sites is Ezidipress, which was established after the August 2014 attacks and which established itself in the field due to its in-depth, less partisan reporting from all geographical and social angles of Yezidism. The people working at Ezidipress are mostly young professionals with little religious background but a sincere interest in those topics. The fact that Ezidipress has offices and staff in all Yezidi territories contributes to the positive popular opinion of the agency.

The diaspora community is largely at odds with itself, or to be more precise, the diaspora organizations are divided and have failed to reach a consensus on religious, political, and social issues. They have also been unable to unify under one central organization. In Germany, for example, Yezidis congregate in small, local associations and try to trump the others in political activism, aide campaigns, and media representation. However, their activities mostly cancel each other out. When each organization tries to organize a meeting (and picture) with the German chancellor Angela Merkel and gain political and financial support from the German government, the results are negligible.

However, efforts are made by Yezidi organizations in the homeland and abroad to use digital media to their advantage because they recognize the broad audience they can reach. In the following, I would like to introduce three mapping projects in which apps, social media, GIS data, and other solutions are used to enhance the understanding of Yezidi history and religiosity.

\section{Mapping Historic Genocides}

The first project started on 15 August 2014, immediately following the first attacks on Sinjar. A team of journalists, academics, and activists described the long-lasting history of anti-Yezidi genocides and the fact that the current one was a continuation of these repeated attacks. Through interactive maps and infographics, the visualization traces those attacks back to the twelfth century. It also shows the usual Yezidi response to the attacks, which is to migrate to nearby or distant areas of safety. By doing so, they have often 
established permanent homes in new territories and had to abandon their former, ancestral homeland.

The collaboration with a major US newspaper allowed for more visibility of the Yezidi discourse of discrimination and migration. The Yezidi community in the United States is still small: perhaps two thousand individuals. However, as Krajeski (2018) shows, reaching out to the strongest political and military power in the world created positive connections and responses. The decision by the Obama administration to rescue the Yezidis from Sinjar Mountain and to bomb ISIS positions is one of these immediate benefits.

The other outcome of this project was for the Yezidi community to contextualize their multilayered history and identity. One of the main obstacles to the development of a strong, unified Yezidi identity is the distribution of Yezidi communities across a number of countries. Here, the community reflects on the notion of a sacred homeland and the loss of it due to the continual impositions of their enemies. It also helps to establish a geographical depository of former and current Yezidi locations, which allows the community to appreciate their geographical diversity and historic depth.

\section{Mapping Yezidi Territory}

The second project is a collaboration between Yezidi activists and scholars from Turkey, Syria, and Iraq with the goal of mapping local Yezidi migration in eastern Anatolia and northern Mesopotamia. This multilayered outcome illustrates where Yezidi communities used to live in Turkey, Syria, and Iraq at specific points in history: 1832, 1892, 1918, 1961, 1975, 1992, 2007, and 2014. These dates coincide with major attacks on the Yezidi communities and subsequent population movements. The final graph shows which communities moved into the former Yezidi territories.

Since the days of independence of their nation states, the ancient communities in the borderland between Turkey, Syria, and Iraq have experienced periods of large-scale population movement, often involuntarily due to displacement, ethnic and religious violence, and government interventions. Under the new circumstances, with the rise of radical Islamist movements, the Yezidi community and other minority groups will be forced out of their traditional spaces, which ultimately will lead to a remodelling of the region's identity landscape.

The mapping of Yezidi migration is significant because it identifies the former and current population development in an understudied area, and 
it will ultimately increase our understanding of the region's ethno-religious diversity. The project aims to trace former and recent Yezidi communities in their homeland and the diaspora by mapping routes of migration and identifying causes and consequences of the movement. It highlights the ongoing process of de-territorialization and identity transformation of the Yezidi community.

\section{Mapping Mass Graves}

This project run by Yazda, a Yezidi NGO in Iraq (unaffiliated with the religious and political leaders), uses satellite and GIS data in addition to local oral sources to locate and identify mass graves around Mount Sinjar.

It was estimated that 3100 Yezidis were killed during the attacks, with nearly half of them executed and the other half dying on Mount Sinjar because of the ISIS siege (Cetorelli et al. 2017). Those who were executed (shot, beheaded, or burned alive) were largely males, but many females - especially older females - were among the victims too. Survivors reported mass executions in many Yezidi villages on both the northern and southern sides of the mountain. After the areas were liberated from ISIS occupation, those reports helped in locating the grave sites. However, technology such as drones and satellite images were needed to physically find the exact locations, because the graves have been ploughed over. They were left for three years, and some areas were further damaged during the military campaigns.

Yazda composed a detailed, interactive map with the location of the sites and information about the victims in an effort to document the genocide against the Yezidi community. Their focus included the collection of survivor testimonies, the identification of mass graves in the Sinjar region, and the recording of the physical destruction of Yezidi material culture and towns to try to prevent them from returning to their homelands and effectively erase their presence from the region. The stated objective was to preserve the memory of what befell the Yezidi community, preserve knowledge about Yezidi culture as it existed in Sinjar prior to the attempted genocide, provide the international community with a detailed and accurate account of the genocide, and collect evidence of crimes against the Yezidis in the effort to secure genocide recognition for the Yezidi case (Yazda 2016, p. 3).

The project is ongoing as more grave sites are discovered. As of now, 68 mass graves have been identified. Efforts to secure and investigate the sites are underway, and survivor accounts from all Yezidi groups and castes are being collected and analysed. 


\section{ISIS Usage of Technology to Enslave Yezidis}

It should be mentioned here that ISIS, too, is very competent in using upto-date media technologies. They have used devices, technology, and social media to recruit new members, to reach out to their constituency and the larger world, and to sell and trade Yezidi sex slaves. The latter have been the focus of this chapter: ISIS members are thought to have used WhatsApp or Telegram to post portfolios of Yezidis girls, women, and families in order to trade or sell them to other ISIS members. The Associated Press reported on these accounts: a girl for sale is 'Virgin. Beautiful. 12 years old [...] Her price has reached $\$ 12,500$ and she will be sold soon' (Hinhant et al. 2016). They also viewed an advertisement on WhatsApp for a mother with a three-year-old and a seven-month-old baby, with a price of $\$ 3700$. 'She wants her owner to sell her', read the posting, followed by a photo (Hinnant et al. 2017). Apparently, ISIS maintains a thorough database with a photograph of the Yezidi women and information about their owners. This knowledge can be shared among other ISIS members who want to purchase a Yezidi slave or who work at the checkpoints, preventing the Yezidis from escaping. The usage of encrypted apps cannot be prevented; Yezidi activists trying to liberate the women can only monitor these transactions. However, sometimes they manage to 'win' an auction and pay the ransom to free their women.

\section{Conclusion}

Technology has had a massive impact on the life and culture of the Yezidis. It has affected their communication, representation, education, and interaction with the non-Yezidi world. As shown in these examples and the arguments brought forward in this chapter, the approach to seeking knowledge in Yezidism has changed dramatically away from a discriminative, elitist process towards a mass culture of learners and contributors. Concurrently, the oral nature of the sacred knowledge has been altered and scripturized, reflecting a higher standard of education and higher awareness of religious topics. This supports the process of reimagining religiosity and historiographies, as it gives voice to previously ignored or silenced groups such as youth, women, and laypeople. Ultimately, this will lead to a transformation of social and religious structures. Allison claims that 'Yezidism will change from an oral religion of orthopraxy to a scriptural religion of orthodoxy' (2001, p. 50). However, the current process of transformation will extend beyond the religious realm.

New media and technology have triggered the changing of gender and generation roles as well as larger processes of identity building within the 
Yezidi community. Apps and maps help the Yezid community to recover from trauma and the disruption of their livelihood. They recreate an image of the past, provide assistance, increase communication, and develop new norms and standards.

Additionally, as a by-product, tools have been created to better safeguard the community from future harm, as these mapping tools have increased our knowledge of how previous attacks were orchestrated. These tools may also help prevent future attacks as they visualize the spatial conditions and circumstances on the ground that have allowed the attacks to occur.

\section{References}

Christine Allison, The Yezidi Oral Tradition in Iraqi Kurdistan (Richmond: Psychology Press, 2001).

Benedict Anderson, Imagined Communities: Reflections on the Origin and Spread of Nationalism (London/New York: Verso Publishers, 2006).

Ordixane Celil and Celile Celile, Zargotina Kurda (Moscow: Nauka Publishers, 1978). Valeria Cetorelli, Isaac Sasson, Nazar Shabila, and Gilbert Burnham G, 'Mortality and Kidnapping Estimates for the Yazidi Population in the Area of Mount Sinjar, Iraq, in August 2014: A retrospective household survey', PLoS Medicine, 14(5) (2017), pp. 1-15.

Brad Coombes et al., 'Indigenous Geographies III - Methodological Innovation and the Unsettling of Participatory Research', Progress in Human Geography, 38(6) (2014), pp. 845-854.

Dabiq Magazine, 7, 2015, Online Resource: https://azelin.files.wordpress. com/2015/o2/the-islamic-state-e2809cdc481biq-magazine-722.pdf (accessed 18 November 2020).

Christine Hine, 'Overview: Virtual Ethnography: Modes, Varieties, Affordances', in Handbook of Online Research Methods, ed. by Nigel G. Fielding, Raymond M. Lee, and Grant Blank (London: Sage, 2008).

Lori Hinnant, Maya Alleuzzo, and Balint Szlanko, 'How ISIS Uses Smart Phone Apps to Sell and Register its Sex Slave Captives', Associated Press, Online Resource: https://www.pbs.org/newshour/world/how-isis-uses-smart-phone-apps-to-selland-register-its-sex-slave-captives (accessed 18 November 2020).

-, 'Islamic State Tightens Grip on Captives Held as Sex Slaves', Associated Press, Online Resource: https://apnews.com/article/7685e2ob2883496abc3dogi1de6 c67ab (accessed 20 November 2020).

Farida Khalaf, The Girl who Escaped ISIS (New Yok: Atria Books, 2017).

Jenna Krajeski, 'The Daring Plan to Save a Religious Minority from ISIS', The New Yorker, 26 (2018). 
Philip Kreyenbroek, Yezidism in Europe - Different Generations Speak about their Religion (Wiesbaden: Harrassowitz, 2009).

Sebastian Maisel, Yezidis in Syria: Identity Building among a Double Minority (Lanham: Lexington Books, 2017).

Memri. Jihad and Terrorism Threat Monitor, 'Islamic State (ISIS) Releases Pamphlet On Female Slaves', 2014, Online Resource: http://www.memrijttm.org/ islamic-state-isis-releases-pamphlet-on-female-slaves.html\#_ednı (accessed 18 November 2020).

Nadia Murad, The Last Girl-My Story of Captivity, and my Fight against the Islamic State (New York: Tim Duggan Books, 2017).

John Postill and Sarah Pink, 'Social Media Ethnography: The Digital Researcher in a Messy', Web Media International Australia, 145(1) (2012), pp. 123-134.

Raoul Ranoa and Jon Schleuss, 'Yazidi persecution spans centuries', Los Angeles Times, 2014, Online Resource: http://beta.latimes.com/world/middleeast/ la-fg-g-yazidi-a-history-of-persecution-20140815-htmlstory.html (accessed 18 November 2020).

Khidir Suleyman and Khalil Jindy, Êzdiyatî: liber Roṣnaya Hindek Têkstêd Aîne Ézdiyan (Baghdad, 1979).

UN Human Rights Council, 'They Came to Destroy - ISIS Crimes Against the Yezidis', 2016, Online Resource: http://www.ohchr.org/Documents/HRBodies/ HRCouncil/CoISyria/A_HRC_32_CRP.2_en.pdf(accessed 18 November 2020).

Yazda Organization, A Report from the Yazda Documentation Project on Mass Graves of Yazidis Killed by the Islamic State Organization or Local Affiliates On or After August 3, 2014, 2016, Online Resource: https://www.yazda.org/wp-content/ uploads/2017/o7/Yazda-Report-on-Mass-Graves-Jan-28-2016-2-Copy-1.pdf (accessed 18 November 2020).

\section{About the Author}

Sebastian Maisel is a full professor of Arabic Language and Translations at Leipzig University. His research focus is on social transformation among rural communities and minority groups, for which he has conducted fieldwork among the Bedouin tribes in Saudi Arabia, the Yezidis in Syria and Iraq, as well as Dinka slave soldiers from Sudan. He primarily uses sources that include oral narratives, material culture, and virtual representations. His publications include The Customary Law of the Bedouins in Northern Arabia (2006), The Kingdom of Saudi Arabia with D. Long (2010), Yezidis in Syria - Identity Building among a Double Minority (2016), and The Kurds: An Encyclopedia of Life, Culture and Society, (2018). 